DOI: $10.14451 / 1.170 .60$

\title{
ИННОВАЦИОННЫЕ МЕХАНИЗМЫ ЛОГИСТИЧЕСКОЙ ДЕЯТЕЛЬНОСТИ
}

\author{
(c) 2019 Потехина Елена Николаевна \\ кандидат экономических наук, доцент \\ Марийский государственный университет \\ 424000, г. Йошкар-Ола, пл. Ленина, 1 \\ E-mail: vilor@mail.ru
}

Внутрифирменная логистика является резервов повышения эффективности деятельности организации. Налаженные и выстроенные бизнес-процессы, механизмы реагирования на внешние вызовы и риски, позволяют организации быть конкурентоспособной в изменяющихся условиях ведения деятельности. Инновационная составляющая грамотно встроенная в систему существующих реалий дает экономический эффект уже в среднесрочной перспективе.

Ключевые слова: логистика, инновационные механизмы, внутрифирменные резервы, бизнес-процесcbl, puck.

Инновационные механизмы внутрифирменной логистики выстраиваются в разрезе бизнес-процессов организации. Предпринимательство сталкивается с вызовами автоматизации, глобализацией и протекционизмом государственных и корпоративных структур. Эти вызовы остро стоят на повестке дня как среднего, так и малого бизнеса. Доминирующее положение государственных, банковских структур и представителей крупного бизнеса сложилось исторически. Актуальным становиться кооперация и интеграция, но не в традиционном их понимании. Предприятия кооперируются по выборочным аспектам деятельности. Например, поставка сырья и материалов о крупного поставщика за рубежом, для выведения из логистической цепочки мелкооптовых представителей. Приобретая напрямую у производителя, формируется единая база данных и распределяется возможность поставок по срокам и местам хранения, объемам, формируется единая торговая площадка. Возможности автоматизации позволяют в едином ключе отслеживать движения и остатки. При этом достигается унификация продукта и его дальнейшее прохождение в цепочке продаж может быть прописано едиными нормами, что так облегчает возможности интеграции и последующей реализации. При этом сокращается стоимость доставки, а это минимально 30 процентная экономия.

Конкурируя в борьбе за покупателя, предприниматели объединяются ради сокращения издержек. Из логистической цепочки исключается ряд затрат вместе с недостаточно квалицированными посредниками.
Построение внутрифирменных алгоритмов работы с клиентами является важной составляющей. На ее основе выстраиваются внутренние регламенты и разрабатывается направляющая форма.

Стандартизация и унификация регламентов необходима для эффективной конкурентоспособной деятельности организации.

\section{ПОСТУПЛЕНИЕ ЗАКАЗА}

Входная информация. Используются все описанные ранее методы. Фиксация происходит с помощью источников интеграции систем. Определяющим моментом является первоисточник прохождения потенциального покупателя в реального.

1. Делаем уточнения, если требуется связанные с номенклатурой товара, качеством, состоянием позиции на складе готовой продукции и в производстве.

2. Определяем способ и сроки оплаты (безналичные/наличные, постоплата /предоплата). Скидки и возможные акции. Уточнение рассрочки платежа. Гарантийные письма. Определяется транспортная компания и возможность самовывоза. Оговаривается срок исполнения обязательств.

3. Вносим заказ в базу учета.

4. Передаем заказ на склад.

Проверка договора поставки

В случае его отсутствия, отправка 2-ух экземпляров с подписью и печатями.

В случае его наличия, но без подписи клиента, напомнить о необходимости отправки подписанного договора.

Контроль обеспечения заказа 
В случае если срок готовности заказа задерживается, урегулировать это с клиентом.

\section{Контроль оплаты заказа}

В случае если заказ укомплектован, но еще не оплачен, уведомить клиента.

Заказ укомплектован.

Заказ оплачен и укомплектован.

Документы на груз.

Данные получателя груза, плательщика

Документы на отгрузку

\section{ОТГРУЗКА}

Получение подписанной товарной накладной.

В случае если клиент не отправил подписанную реализацию, просим отправить сканированный документ.

В начале недели вносим информацию о подписанных накладных за прошлую неделю в базу 1: C.

Вводим данные в отчет за неделю по продажам.

Сортируем в папки.

Контроль качества.

Через 3 дня после ориентировочного прибытия груза, позвонить клиенту и узнать отзыв о нашей работе и товаре

\section{ПЕРЕХОД НА НОВУЮ ПРОДАЖУ}

Стандартизация каждого элемента и определение ответственных за каждый этап необходимо в целях контроля и соблюдения всех регламентов операции. Необходимо четкое понимание на каком этапе возможен срыв и какие критерии оценки возможны. Стимулирование отдела продаж возможно при формировании единых стандартизованных и регламентированных критериев с единой формой контроля и необходимостью вовлечения всех участков на получение общего результата.

Автоматизация и отслеживание не возможна без современных инновационных систем обработки информации, заложенных в единый механизм.

Регламент может быть представлен в учетных форма:

1. Клиент проявил интерес к компании или мы нашли клиента.

2. Направляется проект базового договора на рассмотрение и подписание контрагенту.

3. В случае несогласия с пунктами договора проводятся переговоры на предмет согласования протокола разногласий.

4. В договоре определяем систему работы с клиентом: способ и порядок оплаты, способ доставки, система подачи заказов.

5. Контрагент вносится в систему учета.

6. После подписания договора получение заказа. Получение заказа может сопровождаться спецификацией к отгрузке, в которой будет прописан ассортимент, цена, срок изготовления продукта, условия поставки.

7. Заказ вносится в систему учета и передается на производство.

8. Заказ может иметь ряд ограничений таких как минимальная сумма заказа, квант поставки / изготовление каждой номенклатурной единицы.

9. В заказе определяется дата запуска и ориентировочная дата изготовления заказа.

10. Необходимые ресурсы для изготовления заказа определяются переходящими на складе остатками или происходит закуп комплектующих, что так же влияет на срок изготовления заказа.

11. При предоплатной системе оплат, с получением заказа выписывается счет на оплату. Обычно после поступления денежных средств на расчетный счет поставщика заказа запускается в производство.

12. При постоплатной системе расчета в спецификации либо договоре прописывается срок оплаты по заказу. В течение __ дней после подписания ТТН (УПД) о получении заказа.

13. При самовывозе после готовности заказа информация о подготовке к отгрузке сообщается покупателю. Представитель покупателя приезжает в назначенные временные ворота с доверенностью от покупателя на получение груза и наличие полномочий на прием товара по количеству.

14. Качество товара обычно можно проверять либо в течение нескольких дней после доставки до местонахождения клиента, либо в течение всего срока годности (так же описывается в договоре).

15. Доставка товара:

- после изготовления заказа продукция доставляется клиенту в указанное место и время;

- доставка осуществляется согласно нормам хранения товара специализированным ТС, если это необходимо;

- поставка сопровождается документами, которыми могут быть УПД и ТН или другой комплект, который так же оговаривается в договоре;

- поставку осуществляет представитель по- 
ставщика;

- представитель присутствует при приемке товара и имеет право подписи в Акте расхождения;

- в случае расхождения по качеству или количеству составляется Акт по расхождения по качеству по форме ТОРГ-12;

- в случае наличия расхождений по накладной по данному акту в УПД вносится корректировка;

- исправленные счет - фактуры передаются покупателю.

Оплата производится по сумме, указанной в исправленных документах.

Данные алгоритмы интегрируются через действующие системы учета.

Стандартизация регламентов продаж предусматривает поэтапную проработку, основанную на единстве и целостности подходов.

Предпринимательская логистическая деятельность основана на принципах реализации системы комплексного подхода в управлении финансовыми производственными, транспортными потоками, человеческим и временным факторами. Логистическая деятельность в области применения является универсальной для всех видов производств, развита в сфере предоставления услуг, в розничной и оптовой торговле.

Виды логистических рисков, непосредственно связанных с предпринимательской деятельностью.

В первую очередь, это коммерческий риск, основа которого состоит в потерях, которые возникают вследствие несоблюдения срок оплаты и поставки товаров, сырья, материалов, несоблюдение стандартов качества выпускаемой продукции и выпуск брака, изменение спроса на рынке, что влечет за собой убытки, связанные с ассортиментным перечнем и т.д. Риск связанный с перевозкой и транспортировкой грузов вследствие аварий, несоблюдения правил перевозки, а также сюда можно отнести риск, связанный с неисправностью техники и оборудования, транспорта и, который влечет за собой нарушение сроков поставки. Риски утраты имущества от действий злоумышленников или случайной гибели имущества, наименее предсказуемы, но с точки зрения страхования являются управляемыми. Отдельно стоит выделить экологический риск, последствия которого не всегда являются явными и носят долговременный характер.
В зависимости от принадлежности к определенным видам потоков и категориям запасов как базовым категориям, классифицируют логистические риски по потокам: материальным, информационным, финансовым, производственным, инновационным.

На предприятиях происходит генерация внутренних потов, влияющих на внешнюю среду. Внешние факторы в свою очередь оказываю существенное давление на финансово-хозяйственную деятельность и отражаются на его эффективности. Важно структурировать существующие риски и понимать, что различные условия накладываются друг на друга и данный эффект наслоения приводит к необратимым последствиям, которое выражается в натурально-стоимостных показателях, а также проявляются информационной составляющей принятия управленческого решения.

Разделение на инновационную, инфраструктурную и производственную сферы в исследованиях посвящённых управлению логистических систем оправдано в первую очередь исходя из разнообразия и многообразия удовлетворения потребностей потребителей и обеспечении действующих базовых условий и могут выражаться в управлении предпринимательской деятельностью на производственные, финансовые и инвестиционные.

Алгоритм работы с логистическими рисками:

Определение риска -> Оценка и анализ -> Подбор методов и приемов управления -> Устранение (профилактика) -> Финансирование -> Контроль и оценка результатов.

В процессе управления логистическим риском, на каждой стадии возникают взаимосвязанные действия, что влечет за собой отступление от четких границ каждой стадии. Все стадии взаимосвязаны и взаимозависимы друг от друга, что выражается в увеличении возникновения потенциального логистического риска. Для минимизации рисков необходимо выстроить чёткую систему критериев и показателей определения неблагоприятных событий, поэтому первая стадия алгоритма является наиболее важной с точки зрения всего механизма деятельности предприятия.

Возможны два варианта сокращения логистических рисков, непосредственно страхование и недопущение их возникновения за счет построения грамотной логистической систе- 
мы, базирующейся на принципах оптимального запаса готовой продукции и материалов на складах, ускорения оборачиваемости, сопровождение поставок от заявки до заявки и других эффективных логистических методах.

Непосредственно страхование в России в настоящее время не имеет оптимальных пакетных продуктов страхования предпринимательских (в том числе логистических рисков) удовлетворяющих всем потребностям рынка. Предпринимателям предлагаются стандартные страховые продукты. Страхование рисков происходит по стандартным продуктам страхования. Для продвижения страхования предпринимательских рисков в России в первую очередь не выработано самой культуры страхования, нет достаточных объемов, отсутствуют гарантии, в том числе от государства. Предпринимательский риск может быть прямым, косвенным, неизбежным. Его определение на прямую завит от принятых норм учета. Например, понятие поручительства по кредитам и займам влечет за собой обязательства по погашению кредита в случае неплатежа заемщика. Но в тоже время само обязательство по поручительству не учитывается на балансе предприятия поручителя и предприятие не может не выплачивать, по существу, по чужим обязательствам и подать на банкротство. Поэтому недопущение наступления риска, рассмотрение всех возможных ситуаций является первооче- редной задача менеджмента.

Минимизация рисков, возникающих в логистической системе, основывается на ряде мероприятий, таких как качественные и количественные методы анализа и оценки риска. Главной задачей качественного анализа риска коммерческого предприятия является определение внешних и внутренних факторов его возникновения и идентификации всех возможных видов риска в базовых и нестандартных бизнес - ситуациях. Количественный анализ предполагает определение численных значений по отдельным видам риска предприятия.

Поскольку риск есть вероятная категория, то в этом смысле наиболее обоснованно с научных позиций характеризовать и измерять его как вероятность возникновения определенного уровня потерь. Таким образом, при всесторонней оценке риска необходимо устанавливать соответствующую вероятность возникновения потерь для каждого звена логистической системы. Своевременный и полноценный учет логистических рисков позволяет не только сэкономить финансовые и производственные ресурсы, но и значительно повысить эффективность всей финансово-хозяйственной, что является в условиях жесткой конкуренции и экономической нестабильности, важным резервом устойчивого развития коммерческого предприятия.

\section{Библиографический список}

1. Потехина Е.Н. Факторы инновационной устойчивости и их влияние на логистическую деятельность // Инновационное развитие экономики. - 2017. № 6(42). С. 149-151.

2. Потехина Е.Н. Управление рисками логистической системы в условиях инновационной экономики // Экономика и управление: проблемы, решения. 2018. Т. 4. № 8. С. 104-111.

3. STATE SUPPORT OF SMALL FORMS OF ECONOMY IN THE APK OF THE REPUBLIC OF MARIY EL AS THE CONDITION OF IMPROVING THEIR INVESTMENT ACTIVITY Gumarova F.Z., Potekhina E.N., Kazakovtseva M.V. В сборнике: Proceedings of the 30th International Business Information Management Association Conference, IBIMA 2017 - Vision 2020: Sustainable Economic development, Innovation Management, and Global Growth 30, Vision 2020: Sustainable Economic development, Innovation Management, and Global Growth. 2017. C. 33333339. 